\title{
Health and ergogenic effects of caffeine
}

\author{
B.H. Jacobson and F.A. Kulling
}

Department of Health Science, School of Health, Physical Education and Leisure, Oklahoma State University, USA

The indiscriminate use of caffeine by people of all ages may present health hazards. The public at large needs to be more informed of the presence of caffeine in commonly consumed foods and beverages, particularly by infants, children and pregnant women. It is the responsibility of all consumers to investigate the caffeine content of suspected products so that intake may be objectively monitored.

Although doubts still exist about the efficacy of caffeine as an ergogenic aid, particularly for exercise of high intensity and short duration, the IOC and the National Collegiate Athletic Association of the US have adopted bans on the use of caffeine to aid sport performance. Currently, both of these organizations prohibit the concentration of caffeine in urine to exceed $15 \mu \mathrm{g}-\mathrm{ml}^{-1}$. That is to say, only very large amounts of caffeine are not permitted at present. Additional research is needed to confirm or deny the contraindications presented by the ingestion of caffeine on a chronic basis.

\section{Introduction}

The history of caffeine is almost as old as mankind, yet surprisingly little research in terms of long term effect exists. A recent upsurge of interest concerning the ergogenic properties of caffeine has resulted in investigations involving mainly endurance. However, strength, movement speed and vision studies are also reported.

Original isolation of caffeine from green coffee beans was first achieved in 1820 by a German scientist and the earliest study of the influence of caffeine in metabolism was carried out in 1850 . Few investigations of caffeine occurred prior to the 1970s, but a growth in scientific interest in the drug resulted from a draft issued by a special committee on drugs generally recognized as safe by the Food and Drug Administration (FDA) of the US Public Health Service ${ }^{1}$.

An ingredient in numerous beverages, foods and proprietary drugs, caffeine is currently the most widespread and indiscriminately used drug available to consumers of all ages. Although caffeine is readily accepted as an ingredient in coffee beverages at about

Address for correspondence: Dr B.H. Jacobson, Dept of Health Science, 102 Colvin Center, Oklahoma State University, Stillwater, Oklahoma 74078-0616, USA

(C) 1989 Butterworth \& Co (Publishers) Ltd 0306-3674/89/010034-07 \$03.00
$100 \mathrm{mg}$ a cup, the xanthine derivative presents itself in a myriad of other sources such as tea, carbonated drinks, chocolates, soft candies, baked goods, frozen dairy products, gelatines, puddings ${ }^{2}$ and over-thecounter medications. Currently the FDA's National Center for Drugs and Biologics lists more than 1000 over-the-counter drugs as having caffeine as an ingredient ${ }^{3}$.

\section{Physiological action}

Caffeine is only one of three xanthine derivatives that have similar physiological reactions. The other xanthine derivatives include theophylline and theobromine which are found in tea and cocoa respectively ${ }^{4}$. Caffeine, theophylline and theobromine are alkaloids structurally identified as 1,3,7-trimethylxanthines. Due to structural similarities, it is thought to facilitate the use of uric acid and purine in the body ${ }^{5}$. Caffeine, readily absorbed orally, rapidly empties from the stomach, and is absorbed from the gastrointestinal tract $^{6}$. Peak blood concentration occurs approximately between 30 and 60 minutes after ingestion ${ }^{7}$.

Caffeine is a powerful CNS stimulant and affects the cardiac muscle, kidneys and possibly certain glands. The drug readily crosses the blood brain barrier ${ }^{8,9}$ and acts directly on the vagal, medullary, and vasomotor centres. ${ }^{10}$ Small amounts of caffeine may alter blood pressure, heart rate, respiratory rate and metabolic rate. ${ }^{11}$ Further physiological responses may include increased urine production and higher blood sugar levels.

The half-life of caffeine ranges from four to six hours to two days, depending on the individual's age, weight, sex, hormonal status and use of oral contraceptives. Tolerance to the effects of caffeine may develop after one to four days of regular consumption of $250 \mathrm{mg}$ thrice daily ${ }^{7}$. Infants and children do not eliminate caffeine as efficiently as adults and the effects of the drug may last as long as three to four days ${ }^{12}$.

\section{Health effects of caffeine}

A 1978 official review committee to the FDA stated that it was not appropriate to include caffeine among the substances generally recognized as safe ${ }^{13}$. Physically, caffeine may impair hand steadiness, induce trembling and tremors and can result in chronic muscle tension $^{5}$. Larger doses of caffeine may produce insomnia, nervousness, irritability, anxiety and wakefulness ${ }^{14}$. 
Unusually high doses of caffeine may cause nausea, diarrhoea and even death ${ }^{15}$. Peptic ulcers, pancreatic cancer $^{16}$ and endocrine tumours ${ }^{17}$ are possible conditions resulting from the use of caffeine ${ }^{16}$.

Caffeine is also believed to be associated with certain breast disorders ${ }^{16}$ because the acceleration of the growth-promoting substance associated with fibrocystic breast disease may be increased by caffeine. One study revealed that 65 per cent of the women with benign lumps and thickening breast tissue experienced complete disappearance of all palpable breast nodules and other symptoms within one to six months after all food substances containing caffeine were eliminated from the $\operatorname{diet}^{18}$.

Recent investigations have found a possible link between caffeine and coronary artery disease, arrhythmias $^{19}$ and elevated levels of cholesterol ${ }^{4}$. Additionally, Jacobson ${ }^{13}$ has suggested a connection between caffeine and birth defects. Jacobson reported that $\mathbf{2 3 . 2}$ per cent of mothers who gave birth to abnormal babies drank eight or more cups of coffee per day $^{13}$.

Since caffeine is available to people of all ages, children are also susceptible to the effects of caffeine. A small child, after consuming only one can of caffeinated carbonated drink, may receive the equivalent of two to three cups of coffee for an adult. One investigator found evidence of tachycardia and insomnia in healthy pre-adolescent children after consuming twelve ounces of cola drink ${ }^{20}$. Furthermore, Silver ${ }^{20}$ added 'children are more susceptible than adults, [and that] we should . . . withdraw these beverages from our children's diet'.

\section{Caffeine in athletics}

Early literature identifies caffeine as a doping agent capable of magnifying physical performance ${ }^{21,22}$. A movement to prohibit the use of caffeine in combination with athletic events began in the $1930 \mathrm{~s}^{23}$. Although caffeine was considered an ergogenic aid, the Medical Commission of the British Commonwealth Games of 1971 concluded that caffeine, as consumed in coffee, could not be considered a doping agent. The following year, the International Olympic Committee (IOC) removed caffeine from the lists of doping agents. However, the continued speculation that caffeine could enhance performance as a doping agent and was readily available without regulatory restraint, prompted the IOC to reconsider its previous ruling. Prior to the 1984 Olympic Games caffeine was again added to the list of doping agents by the IOC. The current illegal dose of caffeine is $15 \mu \mathrm{g} \mathrm{ml}^{-1}$ urine. This dose is equivalent to between 500 and $600 \mathrm{mg}$ caffeine or five to six cups of coffee in a one to two hour period.

Studies regarding any ergogenic effects of caffeine in all areas have found confusing and confounding results. Many investigations similar in nature have further confused the issue by employing differences in protocols. Most studies involving human subjects have administered caffeine to only small groups of subjects. Additionally, many of the investigations did not distinguish between subjects who may have been tolerant to the drug prior to testing and others. The following summary of the ergogenic effects of caffeine is divided into these segments: endurance, strength, reaction and movement time, coordination, vision and alertness.

\section{Endurance}

The possible efficacy of caffeine as an endurance enhancing aid was initially recognized in the late $1800 \mathrm{~s}^{24}$. Laboratory experimentation attempting to elucidate this relationship can be traced to the early 1900s when Schirlitz found caffeine to increase work output during cycle ergometry ${ }^{25}$. During the mid 1900s, Asmussen and Bøje ${ }^{26}$ found caffeine capable of overcoming fatigue effects during exhaustive cycle ergometry with a task of 'longer' duration. More recently, Ivy and associates $^{27}$ demonstrated that caffeine $(250 \mathrm{mg})$ increases total work output during prolonged $(2 \mathrm{~h})$ bicycle ergometry. Similarly, Costill and others ${ }^{28}$ found caffeine $(330 \mathrm{mg})$ capable of increasing time to exhaustion during submaximal (80 per cent $\mathrm{VO}_{2}$ max) cycle ergometry, while McNaughton ${ }^{29}$ demonstrated larger caffeine doses $\left(10 \mathrm{mg} \cdot \mathrm{kg}^{-1}\right.$ and $\left.15 \mathrm{mg} \cdot \mathrm{kg}^{-1}\right)$ capable of increasing exercise time during a much shorter, incrementally progressive, cycle ergometry test.

This array of findings demonstrating a positive influence of caffeine on endurance are opposed by an equally convincing body of research which fails to show caffeine enhancement in endurance activities. Perkins and Williams found three different caffeine doses $\left(4,7\right.$, and $\left.10 \mathrm{mg} \cdot \mathrm{kg}^{-1}\right)$ had no influence on time to exhaustion during short, incrementally progressive, cycle ergometry ${ }^{30}$. In similar cycle protocols, Toner and others ${ }^{31}$ using $305 \mathrm{mg}$ caffeine, Powers and others ${ }^{32}$ and Gaesser and Rich $^{33}$ both using $5 \mathrm{mg} \cdot \mathrm{kg}^{-1}$, failed to demonstrate that caffeine increases exercise time to exhaustion. Finally, Butts and Crowell ${ }^{34}$ found no change in time to exhaustion during submaximal (75 per cent $\mathrm{VO}_{2}$ max) cycle ergometry as a result of ingesting $300 \mathrm{mg}$ caffeine.

In an attempt to resolve these dichotomous findings, a close examination of exercise protocols may be helpful. This is of importance since exercise intensity and duration are inversely related. Thus, exercise eliciting maximal oxygen uptake may be tolerated for less than one minute while submaximal exercise (60-85 per cent $\mathrm{VO}_{2}$ max) may be endured for several hours by subjects who are habitually active ${ }^{35-38}$.

Of the studies cited which failed to demonstrate that caffeine is an endurance-enhancing aid, all but on $e^{34}$ employed exercise protocol intensities or progressional intensities which limited or would limit exercise duration to several minutes at best. Likewise, of those studies cited which demonstrate a positive effect of caffeine, all but on ${ }^{29}$ utilized intensities which permitted or would permit exercise duration to be measured in hours. In the study of Butts and Crowell ${ }^{34}$ average exercise duration ranged between 60 and $70 \mathrm{~min}$, yet caffeine failed to increase exercise time in both men and women. In the McNaughton ${ }^{29}$ study, average exercise duration was in the seven minute range, yet both a 10 and $15 \mathrm{mg} \cdot \mathrm{kg}^{-1}$ dose increased cycling time to exhaustion. The $15 \mathrm{mg} \cdot \mathrm{kg}^{-1}$ dose was approximately three times greater than the average dose cited in other studies. In contrast to the findings of McNaughton ${ }^{29}$, Perkins and Williams ${ }^{30}$, using a similar protocol, found $10 \mathrm{mg} \cdot \mathrm{kg}^{-1}$ caffeine to be ineffective in increasing exercise time. 
With these exceptions, it would appear that caffeine tends to be effective in prolonging exercise of durations exceeding one hour. In an attempt to explain this phenomenon, a brief review of human bioenergetics may be warranted. Exercise of high intensity $(>85$ per cent $\mathrm{VO}_{2}$ max) results in the accumulation of organic acid metabolites which impair mitochondrial enzyme activity, thereby severely limiting energy production and exercise duration ${ }^{39}$. Exercise of lower intensity (60-85 per cent $\mathrm{VO}_{2}$ max) does not result in increased accumulation of organic acids, since the slight increase is accordingly removed by the liver, kidneys, heart and active muscles ${ }^{40-44}$. Exercise intensities of between 60 and 85 per cent $\mathrm{VO}_{2}$ max would appear to be duration limited as a result of glycogen depletion, which may restrict energy production since carbohydrate substrates are essential to Krebs Cycle function ${ }^{45-48}$. At exercise exceeding 85 per cent $\mathrm{VO}_{2}$ max, the rate of muscle glycogen utilization is rapid but considerable quantities remain at exhaustion ${ }^{47}$.

Costill and associates demonstrated that heparin-induced increases in plasma free fatty acid (FFA) resulted in decreased muscle glycogen depletion during $30 \mathrm{~min}$ of treadmill exercise at 70 per cent $\mathrm{VO}_{2} \max ^{28}$. Therefore, the suggestion that caffeine is an enduranceenhancing aid at predominantly aerobic intensities (60-85 per cent $\mathrm{VO}_{2}$ max), may be due to the drug's ability to spare glycogen by increasing fat metabolism and/or reducing carbohydrate metabolism ${ }^{39}$.

Employing aerobic exercise intensities in combination with caffeine, a number of investigations have suggested one or more of the following glycogen-sparing mechanisms: increased plasma FFA levels ${ }^{27}$; increased plasma glycerol levels ${ }^{39}$; decreased respiratory exchange ratio $(R)$ values ${ }^{27,39,49,50}$. Equivocally, Butts and Cromwell did not find a difference in $R$ with caffeine ingestion during approximately one hour of exercise at between 65 and 70 per cent $\mathrm{VO}_{2} \max ^{34}$, while Casal and Leon found an increase in FFA concentration following caffeine ingestion prior to exercise, but the increase did not remain during a $45 \mathrm{~min}$ treadmill run at 75 per cent $\mathrm{VO}_{2}$ max ${ }^{51}$. Essig and associates determined, through comparative muscle biopsies, that caffeine is capable of reducing glycogen depletion by 42 per cent ${ }^{49}$.

In summary, there appears to be a strong case for the efficacy of caffeine as an endurance-enhancing aid during exercise eliciting between 60 and 85 per cent $\mathrm{VO}_{2}$ max where the duration of exercise approaches or exceeds one hour. At higher intensities and shorter durations, results are equivocal but suggest that caffeine is ineffective in enhancing performance. The primary reason for the improved endurance during exercise of longer duration would appear to be increased fat utilization leading to a glycogen-sparing effect. However, two studies suggest enhanced neuromuscular facilitation in response to caffeine ${ }^{39,52}$. These authors feel the following areas provide opportunities for additional study: the use of multiple, graduated caffeine dosages based on body weight; differentiation of subjects on the basis of $\mathrm{VO}_{2}$ max and/or prior exercise history; differentiation of subject based upon habitual caffeine use; differentiation of exercise tasks with respect to intensity, duration and modality and the inclusion of actual competitive conditions in addition to controlled laboratory situations.
Finally, there are a number of risks to consider before using caffeine in an attempt to improve performance. Its diuretic effect and the propensity to provoke cardiac arrhythmias are well documented ${ }^{38}$. Consequently, risks of caffeine use may outweigh potential benefits under hot, humid conditions or for those with a compromised cardiovascular electrophysiology.

\section{Caffeine and muscular strength}

Caffeine is absorbed according to the water content of the tissue, which consequently results in the heaviest concentrations of caffeine in muscle tissue ${ }^{53}$. Reported effects of caffeine on muscle include enhanced contractile status, altered patterns of recruitment, potentiation of the rate of subrate utilization ${ }^{9}$, facilitation of neuromuscular transmission ${ }^{54}$ and calcium manipulation $^{55}$.

A review of the effect of caffeine on neuromuscular properties indicates that a majority of investigations have utilized in vitro animal or insect skeletal muscle tissue. The following summary of research involves nonhuman muscle tissue which will be followed by studies of maximal voluntary contractions in humans under the influence of caffeine.

Varagic and Zugic ${ }^{56}$ suggested that caffeine may not only have an effect on neuromuscular transmission due to an increase in acetylcholine, but also that the drug enhances muscle twitch response by either direct or indirect stimulation. Correspondingly, Waldek postulated that caffeine may reduce the threshold of neuronal excitability ${ }^{54}$. However, Butcher and Sutherland ${ }^{57}$ found similar potentiating effects in denervated muscle after caffeine treatment.

Bianchi ${ }^{58}$ found caffeine to reduce membrane binding of calcium in the myoplasm, which subsequently increased calcium permeability and ionic activity in skeletal muscle. Bianchi ${ }^{58}$ also found that low doses of caffeine promoted striated muscle shortening from resting length and high doses caused 'contractures'. Several investigations have noted caffeine-induced muscle contractures ${ }^{6,59-61}$ which may be linked to a lower mechanical threshold of the muscle tissue $\mathrm{e}^{60,62}$.

The notion that caffeine primarily effects the calcium transport mechanisms within the muscle tissue is well documented. Muscle contractures usually caused as a result of caffeine treatment are absent in calcium-depleted muscle tissue $e^{63}$ and no effect has been found on myofilaments ${ }^{62}$. Consequently, the tension generating action of caffeine on muscle tissue is thought to be calcium-dependent ${ }^{62}$.

In examining the effect of caffeine on calcium transport, Fabiato and Fabiato ${ }^{64}$ suggested that caffeine generates a release of calcium from the reticular system, thereby provoking muscle contraction. Other investigations indicate caffeine as an agent that promotes a decrease in the rate of calcium uptake by the sarcoplasmic reticulum ${ }^{65,66}$ and/or an increase in permeability of the sarcoplasm ${ }^{55}$. Butcher and Sutherland ${ }^{57}$ found caffeine to increase intracellular cyclic AMP levels which may promote reconversion of glycogen to glucose (glycogenolysis) in the liver ${ }^{10,67}$. The process of glycogenolysis provides a rapid emergence of glucose available for muscular contraction. Additionally, Van Handle ${ }^{9}$ suggests a synergistic 
effect of caffeine and adrenaline that may increase glucose-6-phosphate which has been shown to increase muscle contractility ${ }^{68}$.

The assumption that vertebrate and insect skeletal muscle tissue is similarly affected by caffeine has led to investigations involving the effect of caffeine on human muscle contraction ${ }^{69}$.

One recent study found no improvements in maximal hand grip strength as a result of the ingestion of $170-500 \mathrm{mg}$ caffeine ${ }^{70}$. Lopes and associates investigated the effects of an oral administration of $500 \mathrm{mg}$ caffeine on voluntary isometric and electrically-stimulated contractions ${ }^{52}$. The subjects performed three maximal voluntary contractions followed by electrical stimulation of the ulnar nerve at 10, 20, 30, 50 and 100 $\mathrm{Hz}$ following at 15-30 s interval between each stimulation. No difference was found between control and experimental groups in the maximal voluntary contraction or with $100 \mathrm{~Hz}$ stimulation. A curve force with stimulation frequency table showed that caffeine produced an increase in tension for all stimulation frequencies lower than $100 \mathrm{~Hz}$. Although a trend toward enhanced endurance was found, there was no significant difference between endurance time between caffeine and placebo group ${ }^{52}$. The authors suggested that failure to generate force at high frequencies of stimulation may be due to a change in excitability of the cell membrane and/or neuromuscular block. They concluded that caffeine had a direct effect on electrically-induced skeletal muscle contraction before and after fatigue, and that no effect was found in muscular endurance $^{52}$.

Williams and associates investigated the influence of $7 \mathrm{mg} \cdot \mathrm{kg}^{-1}$ caffeine on maximal motor unit activation, isometric force production (handgrip) and muscular endurance $^{71}$. The results indicated a slightly higher, but statistically insignificant, activation of motor units, and no difference in isometric force or muscle endurance. Furthermore, Williams and others found caffeine to produce 'little' effect in EMG tracings during submaximal and maximal contractions when compared with control ${ }^{71}$. The authors concluded that the caffeine-related improvements in contractility and endurance evident in vitro due to calcium engineering by the reticular system were not evident in their investigation and the absence of EMG difference may be due to the specific muscle investigated.

Bond and associates were the first to investigate the effect of caffeine on voluntary dynamic contraction ${ }^{72}$. Using caffeine in a dose $5 \mathrm{mg} . \mathrm{kg}^{-1}$ and a placebo, tests included isokinetic knee flexion and extension at selected velocities of 30,150 and 300 degrees. $\mathrm{s}^{-1}$. No significance was observed between the experimental and control groups. The authors concluded that caffeine at low doses has no influence on muscle function at low, moderate, and high velocities of contraction.

An unpublished observation in our laboratory, using $300 \mathrm{mg}$ and $600 \mathrm{mg}$ caffeine, indicated similar results for maximal torque as those of Bond et al..$^{72}$. Additionally, no difference in anaerobic muscle endurance was evident as a result of 15 repetitions at 300 degrees. $\mathrm{s}^{-1}$ in knee movement.

\section{Reaction time and movement time}

Several inconsistencies have been reported in studies investigating the effect of caffeine on response time and speed of movement. This matter is further complicated by differences in experimental protocol, subject tolerance and its variation in dose used in the experiments. An early study found that typing speed improved with 65-130 mg caffeine and that a dose of $390 \mathrm{mg}$ caffeine resulted in poor performance and tremors ${ }^{73}$. In a study using $300 \mathrm{mg}$ caffeine, Thorton found faster reaction times compared with control ${ }^{74}$. Wenzel and Rutledge reported dose-related improvements in simple reaction time and inverse relationships with complex reaction time as a result of $100 \mathrm{mg}$ and $300 \mathrm{mg}$ caffeine $\mathrm{e}^{75}$. Cheney, in two separate investigations, found $3.3,3.6 \mathrm{mg} \mathrm{kg}$ caffeine ingestion brought about varied results in discriminatory reaction time and that a dose of $5 \mathrm{mg} \cdot \mathrm{kg}^{-1}$ body weight always decreased reaction time $\mathrm{e}^{76,77}$.

Smith and others reported a significant facilitative effect on choice reaction time as a result of $200 \mathrm{mg}$ caffeine $^{78}$. A recent investigation by this author noted significantly improved movement time and reaction time scores after administering $300 \mathrm{mg}$ caffeine but found no significant improvements in either reaction or movement time following a $600 \mathrm{mg}$ dose $^{79}$. The aforementioned study led to the conclusion that a dose response relationship might exist and that perhaps a saturation point of caffeine was reached with the higher dose $e^{80}$.

\section{Coordination}

The scant literature regarding the effects of caffeine on motor coordination has produced largely negative results. Graf stated that caffeine ingestion resulted in undesirable effects on motor coordination ${ }^{81}$. Goldstein and associates, utilizing a coordination test involving trace-drawing of vertical lines, found that $150 \mathrm{mg}$ and $300 \mathrm{mg}$ caffeine had 'no effect upon coordination, as measured by this test ${ }^{\prime 22}$. Putz-Anderson and co-workers found a 'small but significant' improvement in a tracking test involving hand-eye coordination as a result of ingestion of $200 \mathrm{mg}$ caffeine ${ }^{83}$.

Differences in testing protocol and doses of caffeine may have accounted for this disparity. Perhaps the fact that $200-900 \mathrm{mg}$ caffeine decreases hand steadiness predisposes a decrease in fine motor coordination $^{73,78,84-86}$. Certainly the study by Goldstein et al. would be influenced by a decrease in hand steadiness ${ }^{82}$.

\section{Influence of caffeine on vision}

Putz-Anderson and associates concluded that a dose of $200 \mathrm{mg}$ caffeine generated significant improvement in visual monitoring during a dual task of tone-detection and compensatory tracking ${ }^{83}$. In an investigation on foveal simultaneous contrast using a small circular test field surrounded by an inducing annulus (multiplefield), Kleman and associates found that caffeine 'not only diminished the enhancement phenomenon but erased $i^{\prime 87}$. Examining visual threshold, Diamond and Cole found that 1.5 and 3.0 grains of caffeine significantly decreased visual threshold luminance when compared with a control group ${ }^{88}$. Diamond and Cole suggested that caffeine causes the 'on' visual pathways to become more sensitive to light and that the 
threshold decreases correspondingly to the increase of the dose ${ }^{88}$.

With regard to perceptual-restructuring tasks, caffeine was found to impair performance in novel perceptual-restructuring tasks and to facilitate the performance task after it was no longer novel ${ }^{89}$. Administering doses of $32,64,128$, and $256 \mathrm{mg}$ caffeine, Lieberman et al. found significantly improved auditory vigilance and visual reaction time as a result of all of the higher doses of caffeine ${ }^{90}$. Additionally, no adverse effects were observed in a barrage of motor performance tests ${ }^{90}$.

\section{Mental alertness}

The stimulating properties of caffeine have traditionally been used to delay sleep and to promote alertness. One of the earliest investigations demonstrated that caffeine at moderately large doses stimulated mental activity $^{91}$. Graf also concluded that caffeine was a strong neural stimulant suitable for improving physical and mental efficiency ${ }^{81}$. Goldstein administered $150-200 \mathrm{mg}$ caffeine in an investigation of wakefulness and found: caffeine prolonged the time required to fall asleep; caffeine disturbed the soundness of sleep; and caffeine-tolerant individuals were distinctly less affected by the drug ${ }^{14}$. Another study involving caffeine and cognitive performance indicated caffeine to be effective in preventing attention lapses ${ }^{92}$.

However, disagreement regarding the effects of caffeine on mental activity and intellectual performance exists. Two studies reported no evidence that caffeine at moderate and moderately large doses stimulated mental activity ${ }^{93}$ and that caffeine had no effect on objectivity measured performance ${ }^{82}$. The latter investigation noted that some of the subjects indicated a feeling of nervousness rather than alertness.

\section{References}

1 Dews, P.D. 'Caffeine: Perspectives from Recent Research', Springer-Verlag, Berlin, 1984

2 Food and Drug Administration. Caffeine: Deletion of GRAS status, proposed declaration that no prior sanction exists, and use on an interim basis pending additional study Fed Regist 1980, 205, 69817-69838

3 Lecos, C. 'The Latest Caffeine Scorecard' FDA Consumer OHHS Publication (FDA 84-2184) Washington DC, Department of Health and Human Services, 1984

4 Graham, D.M. Caffeine - its identity, dietary sources, intake, and biological effects Nut Rev 1978, 36, 97-102

5 Stephenson, P.E. Physiologic and psychotropic effects of caffeine on man J Am Diet Assn 1977, 71, 240-247

6 Axelrod, J. and Reichenthal, J. 'The fate of caffeine in man and a method for its estimation in biological material J Pharmacol Exper Therap 1953, 107, 519-523

7 Robertson, D., Wade, D., Workman, R., Woosley, R.L., and Oats, J.A. Tolerance to the humoral and hemodynamic effects of caffeine in man J Clinic Invest $1981,67,1111-1117$

8 Olendorf, W.H. Brain uptake of metabolites and drugs following carotid arterial injections Trans Am Neur Assn 1971, 96, 46-50

9 Van Handle, P.J. Caffeine. In 'Ergogenic Aids in Sport Williams, M. (ed), Champaign, Ill, Human Kinetics Pub Co, 1983

10 Syed, I.B. The effects of caffeine J Am Pharmacol Assn $1976,16,568-572$
11 Lombardo, J.A. Stimulants and athletic performance (part 1 of 2) Amphetamines and caffeine Physician and Sportsmed 1986, 14, 128-140

12 Caffeine Contemporary Nutrition Newsletter 5 May 1984

13 Jacobson M. Caffeine's role in birth defects Family Health 1978, 3, 20-22

14 Goldstein, A. Wakefulness caused by caffeine NaunynSchmiedebergs Arch Pathopharmacol 1964, 248, 269-270

15 Schlaadt, R.G. and Shannon, P.T. 'Drugs of Choice, Current Perspectives on Drug Use' (2nd ed) PrenticeHall, Englewood Cliffs, New Jersey, 1986

16 Grady, D. Don't get jittery over caffeine Discover 1986, 7, 73-79

17 Food Chemical News 1977, Sept 25-61

18 Minton, J.P. Response of fibrocystic disease to caffeine withdrawal and correlation of cyclic nucleotides with breast disease Am J Obstet Gynecol 1979, 135, 157-158

19 Prineas, R.J., Jacobs, C.R., Crews, R.S. and Blackburn H. Coffee, tea, and VPB J Chronic Disease 1980, 33, 67-73

20 Silver, W. Insomnia, tachycardia, and cola drinkers Paediatrics 1971, 47, 35

21 Pickering, J.W. Observations on the physiology of the embryonic heart J Physiol London 1893, 14, 383-466

22 Rivers, $W$. and Weber, $H$. The action of caffeine on the capacity for work J Physiol 1907, 36, 33-47

23 Bøje, O. Doping Bulletin of the Health Organization of the League of Nations 1939, 8, 439-369

24 Alles, G. and Feigen, G. The influence of benzadrine on work decrement and patellar reflex Am J Physiol $1942,136,392-400$

25 Schirlitz, K. Uber caffein bei ermiiender muskelarbeit Internationale Zeitschrift fur Angewanote Physiologie Einschlessligh Arbetsphysiologie 1930, 2, 273-277

26 Asmussen, E. and Bøje, O. The effect of alcohol and some drugs on the capacity to work Acta Physcol Scand $1948,15,109-118$

27 Ivy, J.L., Costill, D.L., Fink, W.J. and Lower, R.W. Influence of caffeine and carbohydrated feedings on endurance performance Med Sci Sports Exer 1979, 11, 6-11

28 Costill, D., Coyle, E., Dalsky, G., Evans, W., Fink, W. and Hoopes, D. Effects of elevated plasma FFA and insulin on muscle glycogen usage during exercise J Appl Physiol 1977, 43, 695-699

29 McNaughton, L. Two levels of caffeine ingestion on blood lactate and free fatty acid responses during incremental exercise Res Q Ex Sports 1987, 58, 255-259

30 Perkins, R. and Williams, M.H. Effect of caffeine upon maximal muscular endurance of females Med Sci Sports Exerc 1975, 7, 221-224

31 Toner, M., Kirkendall, D., Chase, J., Delio, D., Cleary, $P$. and Fox, E. The effect of caffeine on the metabolic and cardiovascular responses to exercise Med Sci Sports Exerc (Abstract) 1980, 12, 109

32 Powers, S., Byrd, R., Tulley, R. and Oalender, T. Effects of caffeine on metabolism and performance during graded exercise Med Sci Sports Exerc (Abstract) $1982,14,176$

33 Gaesser, G. and Rich, R. Influence of caffeine on blood lactate response during incremental exercise Med Sci Sports Exerc 1984, (Abstract) 16, 121-122

34 Butts, N. and Crowell, O. Effect of caffeine ingestion on cardiorespiratory endurance in men and women Res Q Ex Sport 1985, 56, 301-305

35 Costill, D. and Fox, E. Energetics of marathon running Med Sci Sports Exerc 1969, 1, 81-86

36 DeVries, H. 'Physiology of Exercise: For Physical Education and Athletics' (4th ed) Wm. C. Brown, Dubuque, 1986

37 Åstrand, P. and Rodahl, K. 'Textbook of Work Physiology: Physiological Basis of Exercise' (3rd ed) McGraw- 
Hill, New York, 1986

38 Brooks, G. and Fahey, T. 'Fundamentals of Human Performance' (1st ed) MacMillan, New York, 1987

39 Costill, D.L., Dalsky, G. and Fink, W. Effects of caffeine ingestion on metabolism and exercise performance Med Sci Sports Exer 1978, 10, 155-158

40 Carlsten, A., Hallgren, B., Jagenburg, R., Svanbrg, A. and Werko, L. Myocardial metabolism of glucose, lactic acid, amino acids and fatty acids in healthy human individuals at rest and at different work loads J Clin Lab Invest 1961, 13, 418-428

41 Harris, P. Bateman, M. and Gloster, J. The regional metabolism of lactate and pyruvate during exercise in patients with rheumatic heart disease Clin Sci 1962, 23, $545-560$

42 Levy, M. Uptake of lactate and pyruvate by intact kidney of the dog Am J Physiol 1962, 202, 302-308

43 Åstrand, P., Hallback, J., Hedman, R. and Saltin, B. Blood lactates after prolonged severe exercise J App Physiol 1963, 18, 619-622

44 Himwick, H., Koskoff, Y. and Nahum, L. Studies in carbohydrate metabolism. I.A., glucose-lactic acid cycle involving muscle and liver J Biol Chem 1929, 85, 571-584

45 Hermansen, L., Hultman, E. and Saltin, B. Muscle glycogen use during prolonged severe exercise Acta Physiol Scand 1967, 71, 129-139

46 Bergstrom, J. and Hultman, E. A study of the glycogen metabolism during exercise in man Scand J Clin Lab Invest 1967, 19, 218-228

47 Saltin, B. and Karlsson, J. Muscle glycogen utilization during work of different intensities Adv Exp Med Biol 1975, 18, 289-299

48 Stryer, L. 'Biochemistry' (2nd ed) W.H. Freeman and Co, San Francisco, 1981

49 Essig, D., Costill, D.L. and Van Handle, P.J. Effects of caffeine ingestion on utilization of muscle glycogen and lipid during leg ergometer cycling Int J Sports Med 1980, 1, 86-90

50 Dickinson, A., Haymes, E., Sparks, K., Dalsky, G., Walsh, D. and Chambers, H. Effects of moderate caffeine ingestion on factors contributing to the quality of endurance performance Med Sci Sports Exerc 1984 (Abstract) 16, 171

51 Casal, A. and Leon, A. Failure of caffeine to affect substrate utilization during prolonged running Med Sci Sports Exerc 1985, 17, 174-179

52 Lopes, J.M., Aubier, M., Jardim, J., Aranda, J.V. and Maclen, P.T. Effect of caffeine on skeletal muscle function before and after fatigue J Appl Physiol 1983, 54, 1303-1305

53 Burg, A.W. Physiological disposition of caffeine Drug Metab Rev 1975, 4, 199-288

54 Waldeck, B. Sensitization by caffeine of central catecholamine receptors J Neural Transmission 1973, 34, 61-72

55 Kavaler, F., Anderson, T.W. and Fisher, V.J. Sarcolemmal site of caffeine's inotropic action on ventricular muscle of the frog Circ Res 1978, 42, 285-290

56 Varagic, V.M. and Zugic, M. Interactions of xanthine derivatives, catecholamines and glucose-6-phosphate on the isolated phernic nerve diaphragm preparation of the rat Pharmacol 1971, 5, 275-286

57 Butcher, R.W. and Sutherland, E.W. Adenosine 3', 5' phosphate in biological materials J Biolog Chem 1962, 237, 1244-1255

58 Bianchi, C.P. Kinetics of radiocaffeine uptake and release in frog sartorius $J$ de Pharmacologie 1962, 138, 41-47

59 Frank, G.B. Utilization of bound calcium in the action of caffeine and certain multivalent cations on skeletal muscle J Physiol 1962, 163, 254-265
60 Huddart, H. Caffeine-induced activation of contraction in stick insect skeletal muscle Comp Biochem Physiol 1969, 28, 1185-1192

61 Luttgau, H.C. and Oetliker, H. The action of caffeine on activation on contractile mechanism in striated muscle fibres J Physiol 1968, 194, 51-74

62 Huddart, H. and Abram, R.G. Modification of excitation-contraction coupling in locust skeletal muscle induced by caffeine J Exp Zool 1969, 171, 48-58

63 Fujino, M. and Fujino, S. Die beziehung zwischen coffein kontraktur und calcium am froschskeletmuskel Arch Ges Physiol 1964, 278, 478

64 Fabiato, A. and Fabiato, F. Dependence of the contractile activation of skinned cardiac cells on the sarcomere length Nature (London) 1975, 256, 54-55

65 Weber, A. The mechanism of the action of caffeine on sarcoplasmic reticulum J Gen Physiol 1968, 52, 61-72

66 Weber, A and Herz, R. The relationship between caffeine contracture of intact muscle and the effect of caffeine on reticulum J Gen Physiol 1968, 52, 750-759

67 McCornack, R.A. The effects of coffee drinking on the cardiovascular system; experimental and epidemiological research Prev Med 1977, 6, 104-119

68 Bowman, W.C. and Raper, C. The effects of adrenalin and other drugs affecting carbohydrate metabolism on contractions of the rat diaphragm Br J Pharmacol 1964, 23, 184-200

69 Isaacson, A. and Sandow, A. Caffeine effects on radiocalcium movement in normal and denervated rat skeletal muscle J Pharmacol Exp Ther 1967, 155, 376-388

70 Bugyi, G.J. The effects of moderate doses of caffeine on fatigue parameters of the forearm flexor muscles Amer Corr Ther J 1980 34, 49-53

71 Williams, J.H., Barnes, W.S. and Gadberry, W.L. Influence of caffeine on force and EMG in rested and fatigued muscle J Phys Med 1987, 66, 169-183

72 Bond, V., Gresham, K., McRae, J. and Tearney, R.J. Caffeine ingestion and isokinetic strength $\mathrm{Br} J$ Sport Med 1986, 20(3), 135-137

73 Hollingsworth, $H$. The influence of caffeine on mental and motor efficiency Arch Phychologie 1912, 3, 1-166

74 Thorton, G. The effects of benzedrine and caffeine upon performance in certain psychomotor tasks $J$ Abnormal Soc Psychol 1939, 34, 96-113

75 Wenzel, D. and Rutledge, C. Effects of centrally acting drugs on human motor and psychomotor performance J Pharmacol Science 1962, 51, 631-644

76 Cheney, R.H. Reaction time after caffeine and coffee consumption J Exp Physiol 1936, 18, 357-369

77 Cheney, R.H. Comparative effect of caffeine per se and caffeine beverage upon the reaction time in normal young adults $J$ Pharmacol Exp Ther 1935, 53, 72-79

78 Smith, D.L., Tong, J.E. and Leigh, G. Combined effects of tobacco and caffeine on the components of choice reaction-time, heart rate, and hand steadiness $J$ Percep Mot Skills 1977, 45, 639-643

79 Jacobson, B.H. and Edgley, B.M. Effects of caffeine on simple reaction time and movement time Aviat Space Environm Med 1987, 58, 1153-1157

80 Jacobson, B.H. and Edwards, S.W. Caffeine and neuromuscular performance American College of Sports Medicine 35th Annual Meeting, Las Vegas, Nevada, May 28, 1987 (unpublished)

81 Graf, O. Increase of efficiency by means of pharmaceutics (stimulants) In German Aviation Medicine WW II $1950,2,1080$ Washington DC, US Government Printing Office

82 Goldstein, A., Warren, R. and Kaiser, S. Psychotropic effects of caffeine in man, I. Interindividual differences in sensitivity to caffeine-induced wakefulness J Pharmacol Exp Ther 1965, 149, 156-159

83 Putz-Anderson, V., Setzer, J.V. and Croxton, J.S. 
Effects of alcohol and methyl chloride on man Psych Rep 1981, 48, 715-725

84 Gilliland, A.R. and Nelson, D. Effect of coffee on certain mental and physiological functions J Gen Psychol 1939, 21, 339-348

85 Adler, H.F., Burkhardt, W.L. and Atkinson, A.S Effect of various drugs on psychomotor performance at ground level and simulated altitudes of 18,000 feet in a low pressure chamber J Aviat Med 1950, 21, 221-236

86 Lehmann, H.E. and Csank, J. Differential screening of phrenotropic agents in man J Clin Psychopathol 1957, 18, 222-235

87 Kleman, J.P., Diamond, A.L. and Smith, E. Effects of caffeine on enhancement in foveal simultaneous contrasts J Exp Psychol 1961, 61, 18-22
88 Diamond, A.L. and Cole, R.E. Visual threshold as a function of test area and caffeine administration Psychon Sci 1970, 20, 109-111

89 Broverman, D.M. and Casagrande, E. Effect of caffeine on performance of a perceptual-restructuring task at different stages of practice Psychopharmacol 1982, 78, 252-255

90 Lieberman, H.R., Wurtman, R.J., Emde, G.G. and Coviella, I.L.G. The effects of low doses of caffeine on human performance Phycopharm 1987, 92, 308-312

91 Switzer, St. C.A. The influence of caffeine upon inhibition of delay J Comp Psychol 1935, 22, 150-163

92 Mitchell, V.E., Ross, S. and Hurst, P.M. Drugs and placebos: Effects of caffeine on cognitive performance Psychol Rep 1974, 35, 875 